\title{
Study of the Lung Function Tests in Healthy Non-Smoking Women Using Different Cooking Fuels
}

\author{
Archana Singh ${ }^{1}$, Namita $^{2}$, Rinku Garg ${ }^{3}$, Mohan Bandhu Gupta ${ }^{4}$ \\ ${ }^{1}$ Assistant Professor, ${ }^{2}$ Assistant Professor, ${ }^{3}$ Professor, Department of Physiology, Santosh Medical College \\ \& Hospital, Ghaziabad, Uttar Pradesh, India, ${ }^{4}$ Professor, School of Medical Sciences and Research, Sharda \\ University, Greater Noida, India
}

\begin{abstract}
Background: In developing country like India still a large group of women use biomass as the cooking fuel in a poorly ventilated cooking area and it is considered as a major risk factor for respiratory diseases. Throughthis study we sought to find the effect of biomass and LPG fuel use on the lung function by stud spirometry.
\end{abstract}

Method: This cross-sectional study was conducted in the rural and urban areas of Ghaziabad. We assessed the lung function in 100 non-smoker females (50 biomass and 50 LPG fuel users) and studies the presence of any correlation between lung function and the duration of exposure.

Results: Compared to LPG users biomass fuel users had significantly lower values of FVC ( $p=0.007)$, FEV1 $(p=0.0024)$, FEV1/FVC $(p<0.0001)$ and PEFR $(p=0.007)$. Statistically significant negative correlation was also found between exposure index and spirometry values in both the groups.

Conclusion: Biomass fuel has a more adverse effect on the lung function and the lung function decline is associated with the exposure duration.

Key words: Biomass, $L P G$, Exposure index, spirometry

\section{Introduction}

Biomass fuels such as crop residues or wood are used in more than half the world's households and a significant proportion of this activity takes place in conditions where much of the airborne effluent is released in the living area. The majority of the solid fuels are burnt in inefficient traditional cooking stoves located in places without adequate ventilation. Biomass, including wood, agricultural residues, charcoal and dung, is widely used for cooking in developing countries. ${ }^{1}$

Pollutants from biomass combustion are a complicated mixture of aerosol (droplets and solid particles) and gases such as CO, PM, hydrocarbons, $\mathrm{NO}_{2}, \mathrm{SO}_{2}$ and others. ${ }^{2}$ Indoor air-pollution by use of biomass fuels is found to have a serious impact on lungs function with a strong association found between length of exposure and respiratory problems. It leads to increase in the incidence of chronic bronchitis, chronic obstructive pulmonary diseases and respiratory infections like pneumonia, tuberculosis. ${ }^{3,4}$

Wood smoke associated toxins causes epithelial cell lining desquamation, pulmonary edema, peribronchial\& perivascular infiltration of Polymorphonuclear cells. These pulmonary lesions worsen dramatically with increasing exposure duration. ${ }^{5}$

More than half of the world's population (52\%) use biomass fuel for cooking. Beside morbidity, burning biomass fuels such as wood, crop waste and dung, or coal is responsible for annual deaths of an around 1.6 million people. ${ }^{6}$ Exposure to indoor air pollution may be responsible for about $4 \%$ of the global health burden. ${ }^{7}$ In India $400-550$ thousand premature deaths occur annually due to use of biomass fuels. ${ }^{8}$

The present study intended to study the effect biomass fueland LPG (Liquefied petroleum gas) on 
pulmonary function in non-smoking healthy women and to study any association if present between exposure duration and lung function decline.

\section{Materials and Methods}

The study was conducted in the department of physiology in association with the department of TB and chest in Santosh medical college and hospital, Ghaziabad. This cross-sectional study was conducted on 100 healthy non-smoking females with no history of cigarette smoke exposure. Among them 50 were biomass fuel users and 50 LPG users. Following approval of the ethical board of institution volunteers were selected randomly from rural as well as from urban area of Ghaziabad through camps conducted. After an informed consent from the subject history was taken which included any history of smoking, location of the kitchen, adequacy of ventilation, type of cooking fuel used, income and any clinically diagnosed disease. Subjects with Cardio respiratory disease, DM, Hypothyroidism, Hypertension, rheumatic disease, collagen vascular disease or any other systemic disease were excluded from the study. Conditions where spirometry is contraindicated like recent surgery, infection, Pneumothorax, thoracic, abdominal or cerebral aneurysms were also excluded from the study.

Standing height was recorded without shoes and with light cloths on a wall mounted measuring tape to the nearest of centimeters. The range of scale was 140$190 \mathrm{~cm}$ in standing posture. Sensitivity of scale was 0.5 $\mathrm{cm}$. Body weight was recorded in $\mathrm{Kg}$ (with shoes off and empty bladder) by using Avery machine, capacity was 120. Body mass index was computed as body weight in kilograms divided by the square of standing height in meters $\left(\mathrm{kg} / \mathrm{m}^{2}\right)$.

Exposure index was calculated as ${ }^{9}-$

EI: number of Hrs for cooking / day $\times$ number of years of Cooking.

SPIROMETRY $^{10}$ : Spirometry was performed with Medspiror which displays spirometry parameters as actual, predicted and percentages predicted values. The subjects were asked to avoid the activities like performing vigorous exercise within 30 min of testing, wearing clothing that substantially restricts full chest and abdominal expansion and eating a large meal within $2 \mathrm{hrs}$ of testing. All the subjects were given time to acclimatized themselves to environmental conditions. Adequate rest was allowed before the test. The nature of the study was explained to the subjects beforehand to avoid any apprehension which could alter the values of the tests. All the readings were taken in the sitting posture and in morning between 10 AM - 2 PM. They were demonstrated the procedure with the emphasis on the importance of taking a full breath and blowing out as fast and hard as possible. Three reading were taken. Highest amongst the three readings was taken as subjects lung function values. Following PFT parameters were analysed for the study:

FVC: Forced Vital Capacity is the total volume of air that the patient can forcibly exhale in one breath.

FEV1: Forced Expiratory Volume in 1st sec. is the volume expired in the first second of maximal expiration after a maximal inspiration and is a useful measure of how quickly full lungs can be emptied.

FEV1/IVC: It is the FEV1 expressed as a percentage of the IVC and gives a clinically useful index of airflow limitation.

PEF: Peak Expiratory Flow. It is the highest flow achieved during the FVC maneuver. It is effort dependent value and reflect subject's effort.

\section{Statistical Analysis}

The data was subjected to statistical evaluation using Graph Pad Prism Version 6 software. Intergroup comparison was done using unpaired ' $t$ ' test. Intergroup comparison for non-parametric data was done using Mann-Whitney $U$ test. Correlations were assessed with Pearson correlation co-efficient and Spearman correlation co-efficient as and when applicable. Results were expressed as mean \pm standard deviation (Mean \pm $\mathrm{SD})$. The $\mathrm{p}$-value $<0.05$ was considered statistically significant. 


\section{Results}

TABLE 1: Shows the basic demographic profile of Biomass users and LPG users.

\begin{tabular}{|l|l|l|l|}
\hline PARAMETERS & $\begin{array}{l}\text { BIOMASS USERS } \\
(\mathbf{n}=\mathbf{5 0})\end{array}$ & $\begin{array}{l}\text { LPG USERS } \\
(\mathbf{n}=\mathbf{5 0})\end{array}$ & p VALUE \\
\hline AGE (years) & $33.84 \pm 6.50$ & $33.60 \pm 5.632$ & 0.897 \\
\hline HEIGHT (cm.) & $156.4 \pm 4.436$ & $156.3 \pm 4.278$ & 0.864 \\
\hline WEIGHT (kg.) & $53.82 \pm 7.537$ & $53.98 \pm 6.441$ & 0.977 \\
\hline B.M.I. (kg/m2) & $22.01 \pm 3.175$ & $22.01 \pm 3.175$ & 0.738 \\
\hline Income (Rs per month) & $2590 \pm 550.4$ & $9500 \pm 1898$ & $<0.0001 * * * *$ \\
\hline
\end{tabular}

${ }^{*} \mathrm{p}<0.05$-significant, ${ }^{* *} \mathrm{p}<0.01$ - highly significant, $* * * \mathrm{p}<0.001$-very highly significant

No statistically significant difference was present in the age, height, weight, BMI among the two groups. But the income was significantly lower in biomass users.

Table-2: Distribution of number of biomass users \& LPG users according to Exposure Index (hrs- years)

\begin{tabular}{|l|l|l|l|}
\hline Exposure index(hrs-years) & Biomass users & LPG users & Total \\
\hline $20-49$ & 23 & 25 & 48 \\
\hline $50-79$ & 8 & 16 & 24 \\
\hline $80-109$ & 19 & 9 & 28 \\
\hline Total & 50 & 50 & 100 \\
\hline
\end{tabular}

${ }^{*} \mathrm{p}<0.05$-significant, $* * \mathrm{p}<0.01$ - highly significant, $* * * \mathrm{p}<0.001$-very highly significant

Table 3 Shows distribution of biomass users \& LPG users according to the exposure index(exposure to cooking fuel). Out of 50 biomass users 23 were found to have 20-49 hrs- years exposure index, followed by 19 subjects in 80-109 hrs- year range. Only 8 women are exposed to 50-79 hrs-years.
Out of 50 LPG users 25 were found in exposure index of 20-49 hrs- years range followed by 16 in 50-79 hrs- years and only 9 subjects with exposure index of 80-109 hrs- years. 
TABLE 3: Shows Spirometry parameters among Biomass users and LPG users

\begin{tabular}{|l|l|l|l|}
\hline PARAMETER & $\begin{array}{l}\text { BIOMASS USERS } \\
(\mathbf{n}=\mathbf{5 0})\end{array}$ & $\begin{array}{l}\text { LPG USERS } \\
(\mathbf{n}=\mathbf{5 0})\end{array}$ & p VALUE \\
\hline FVC (liters) & $2.447 \pm 0.464$ & $2.737 \pm 0.526$ & $0.007^{* *}$ \\
\hline FEV1(liters) & $1.890 \pm 0.429$ & $2.201 \pm 0.471$ & $0.0024^{* *}$ \\
\hline FEV1/IVC (\%) & $3.460 \pm 0.511$ & $3.921 \pm 0.878$ & $<0.0001^{* * * *}$ \\
\hline PEFR (liters/sec.) & $0.767 \pm 0.051$ & $0.802 \pm 0.045$ & $0.007^{* *}$ \\
\hline
\end{tabular}

${ }^{*} \mathrm{p}<0.05$-significant, ${ }^{* *} \mathrm{p}<0.01$ - highly significant, $* * * \mathrm{p}<0.001$-very highly significant

A significantly lower FVC, FEV1, FEV1/FVC and PEFR values were found in biomass users compared to LPG users (table 3).

Fig 1: Correlation between Exposure index and FVC among Biomass fuel users.

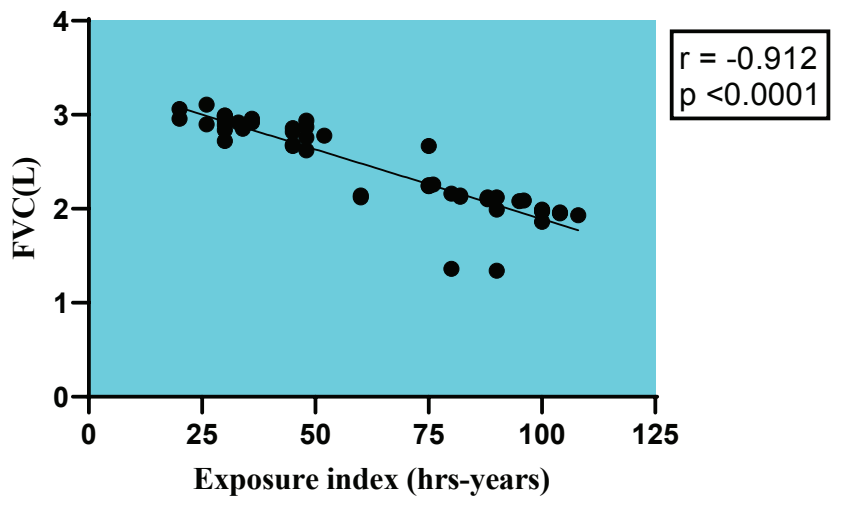

$*_{\mathrm{p}}<0.05$-significant, $* * \mathrm{p}<0.01$ - highly significant, $* * * \mathrm{p}<0.001$-very highly significant

Fig 2: Correlation between Exposure index and FEV1/FVC among Biomass fuel users.

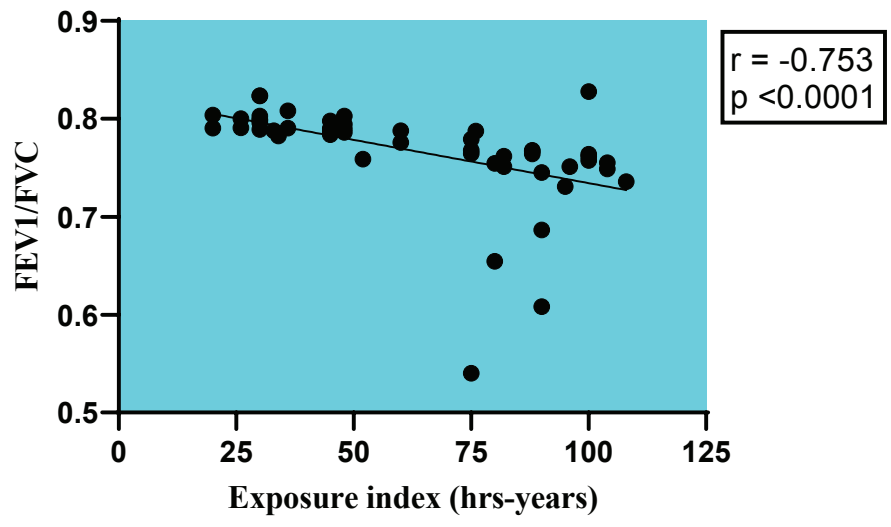

${ }^{*} \mathrm{p}<0.05$-significant, ${ }^{* *} \mathrm{p}<0.01$ - highly significant, ${ }^{* * *} \mathrm{p}<0.001$-very highly significant 
Fig 3: Correlation between Exposure index and FVC among LPG users.

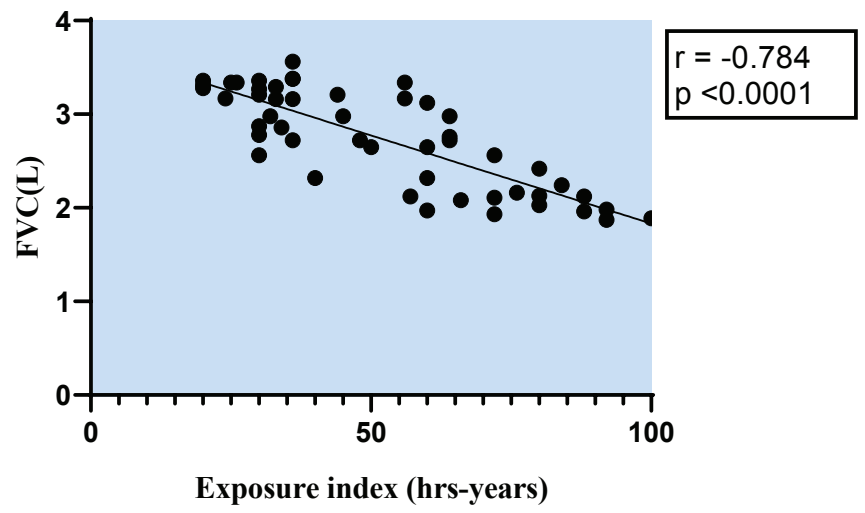

${ }^{*} \mathrm{p}<0.05$-significant, $* * \mathrm{p}<0.01$ - highly significant, $* * * \mathrm{p}<0.001$-very highly significant

Fig 4: Correlation between Exposure index and FEV1/FVC among LPG users.

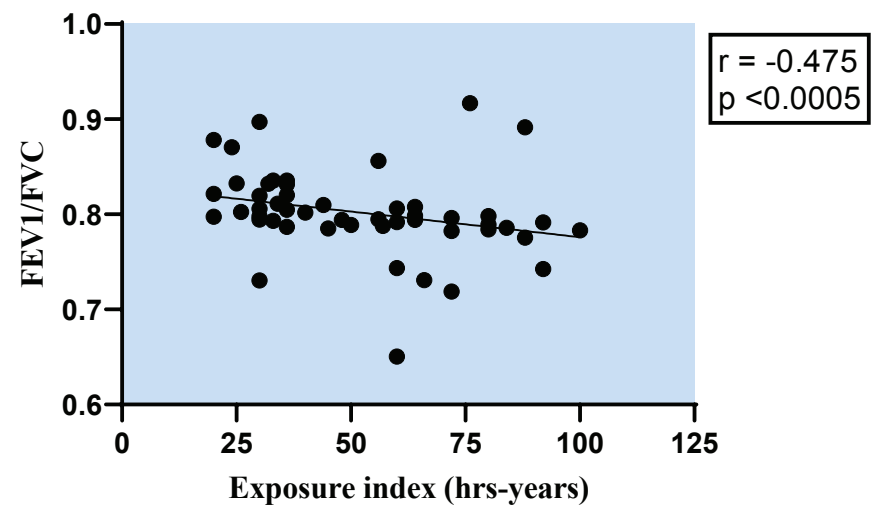

${ }^{*} \mathrm{p}<0.05$-significant, ${ }^{* *} \mathrm{p}<0.01$ - highly significant, ${ }^{* * *} \mathrm{p}<0.001$-very highly significant

The mean value of exposure index in biomass users was $62.52 \pm 28.09$ and among LPG users was $51.94 \pm$ 22.75 and the difference was statistically significant $(p=0.041)$. When correlation analysis was done between exposure index and spirometry values,we found a significant negative correlation both in the biomass group and LPG group. In both the groups we found that values of FVC, FEV1, FEV1/FVC and PEFR significantly decreased with an increase in the exposure index.

\section{Discussion}

The present study was conducted to observe the effect of biomass smoke on lung functions of healthy non-smoking females and to compare the lung function between women using biomass and LPG as cooking fuel.Weenrolled equal number of LPG and biomass fuel users and studied the lung function among them through spirometry. Since we have taken only nonsmoker females and also avoided confounding variables like passive smoking, it helped us to evaluate the effects of biomass combustion exposure alone on pulmonary function.

The two groups did not have any significant difference in their demographic profile like age, sex, height, weight and BMI. But the two groups had significant difference in their incomes. This might be one of the main reasons for their preference of the cooking fuel used.

In our study we found a significant difference in FVC, FEV1, PEFR and FEV1/FVC values between the biomass and LPG users. The results showed that there is a greater deleterious effecton lung functionin biomass 
fuel user than LPG. The duration of exposure was also significantly more in the biomass fuel users which might be an additional factor contributing to the harmful effects seen. When we further analyzed the correlation between exposure and spirometry parameters, we found significant decline in lung function with increase in exposure index in both the groups. This signifies that both the kind of fuels may have a deleterious effect on the lung function. Since the spirometry parameters were significantly lower in biomass users than LPG, we can say that biomass smoke has more hazardous effects on the lung function.

Previously also many studies have shown similar results. Da Silva LF et al. at in their study found that long term exposure to biomass smoke is associated with increased prevalence ofrespiratory symptoms and reduced lung function. They found that symptoms like cough, wheezing and dyspnea are more common in them along with decreased FEV1 and FEV1/FVC ratio. ${ }^{11}$ In a study done by Stapleton EM et al. normal spirometry was found in $40 \%$ of LPG users and only $10 \%$ in the biomass fuel user. $60 \%$ of both the groups had restrictive pattern (post bronchodilator $\mathrm{FEV}_{1} / \mathrm{FVC}>90$ ). The remaining biomass users $(30 \%)$ had respiratory obstruction (post $\left.\mathrm{FEV}_{1} / \mathrm{FVC}<80\right) .{ }^{12}$ Sukhsohale ND et al. concluded in their study that women who use biofuel suffer more from different health problems like eye irritation, cataract, headache, diminution of vision and respiratory illnesses like chronic bronchitis. Lower PEFR was found in them and the prevalence of symptoms was associated with increased exposure index. ${ }^{13}$

Studies have reported exposure to biomass to be a significant risk factor for lung diseases. ${ }^{4,14,15}$ The biomass smoke is found to be an independent etiologic factor for COPD in non-smokers. ${ }^{16}$ It is found that chronic exposure to biomass smoke leads to deposition of organic and inorganic substances like carbon particles, iron, lead, cadmium, silica, phenol, hydrocarbon complexes. This cause oxidative damage and inflammation in the airways and alveoli leading to lung pathologies. ${ }^{5,17}$ Considering the harmful effect of biomass fuel use on lung function, interventions focusing towards finding a more costeffective safer cooking method and increasing awareness regarding better cooking practices is required.
The limitation of our study is that we didn't perform the reversibility test in spirometry which could have given a clearer picture about the obstruction in the lung. The degree of exposurewas calculated according to the exposure index which is based on memory andhow the participant recalls the cooking duration, which could be a biasing factor.Details like exposure to industrial pollution should also had been included to rule out its effect on lung function.

In conclusion, we can say that use of biomass fuel is associated with greater reduction in lung function in comparison to LPG. This effect is dependent on both the magnitude and duration of exposure.

\section{Conflict of Interest: Nil}

\section{Source of Funding: Self}

Ethical Clearance:Ethical clearance taken from the ethical board of the institution.

\section{References}

1. Bruce N, Perez-Padilla R, Albalak R. Indoor air pollution in developing countries: a major environmental and public health challenge. Bulletin of the World Health Organization. 2000 Jan;78(9):1078-92.

2. Bilsback KR, Dahlke J, Fedak KM, Good N, Hecobian A, Herckes P et al. A Laboratory Assessment of 120 Air Pollutant Emissions from Biomass and Fossil Fuel Cookstoves. Environ Sci Technol. 2019 Jun 18;53(12):7114-7125.

3. MbatchouNgahane BH, Afane Ze E, Chebu C, Mapoure NY, Temfack E, Nganda M et al. Effects of cooking fuel smoke on respiratory symptoms and lung function in semi-rural women in Cameroon. Int J Occup Environ Health. 2015;21(1):61-5.

4. Fullerton DG, Bruce N, Gordon SB. Indoor air pollution from biomass fuel smoke is a major health concern in the developing world. Trans R Soc Trop Med Hyg. 2008 Sep;102(9):843-51.

5. Lal K, Mani U, Pandey R, Singh N, Singh AK, Patel DK et al. Multiple approaches to evaluate the toxicity of the biomass fuel cow dung (kanda) smoke. Ecotoxicol Environ Saf. 2011 Oct;74(7):2126-32. 
6. Indoor air pollution and household energy [Internet]. World Health Organization. World Health Organization; 2010 [cited 2021Jan12]. Available from: https://www.who.int/heli/risks/ indoorair/indoorair/en/

7. Bruce N, Perez-Padilla R, Albalak R. Indoor air pollution in developing countries: a major environmental and public health challenge. Bulletin of the World Health Organization. 2000 Jan; 78(9):1078-92.

8. Smith, Kirk R. "National Burden of Disease in India from Indoor Air Pollution." Proceedings of the National Academy of Sciences of the United States of America 97, no. 24 (2000): 13286-3293. Accessed January 10, 2021. http://www.jstor.org/stable/123694.

9. Köksal H, Saygı A, Sarıman N, Alıcı E, Yurtlu Ş, Y1lmaz $\mathrm{H}$ et al. Evaluation of clinical and functional parameters in female subjects with biomass smoke exposure. Respir Care. 2013 Mar;58(3):424-30. doi: 10.4187/respcare.01772. PMID: 23443283.

10. Miller MR, Hankinson JA, Brusasco V, Burgos F, Casaburi R, Coates A et al. Standardisation of spirometry. European respiratory journal. 2005 Aug 1;26(2):319-38.

11. da Silva LF, Saldiva SR, Saldiva PH, Dolhnikoff M; Bandeira Científica Project. Impaired lung function in individuals chronically exposed to biomass combustion. Environ Res. 2012 Jan;112:11-7.
12. Stapleton EM, KizhakkePuliyakote A, Metwali N, Jeronimo M, Thornell IM, Manges RB et al. Lung function of primary cooks using LPG or biomass and the effect of particulate matter on airway epithelial barrier integrity. Environ Res. 2020 Oct; 189:109888.

13. Sukhsohale ND, Narlawar UW, Phatak MS. Indoor air pollution from biomass combustion and its adverse health effects in central India: an exposureresponse study. Indian J Community Med. 2013 Jul;38(3):162-7.

14. Regalado J, Pérez-Padilla R, Sansores R, Páramo Ramirez JI, Brauer M, Paré P et al. The effect of biomass burning on respiratory symptoms and lung function in rural Mexican women. Am J Respir Crit Care Med. 2006 Oct 15;174(8):901-5.

15. Bruce N, Dherani M, Liu R, Hosgood HD 3rd, Sapkota A, Smith KR et al. Does household use of biomass fuel cause lung cancer? A systematic review and evaluation of the evidence for the GBD 2010 study. Thorax. 2015 May;70(5):433-4.

16. Liu S, Zhou Y, Wang X, Wang D, Lu J, Zheng J et al. Biomass fuels are the probable risk factor for chronic obstructive pulmonary disease in rural South ChinaThorax 2007;62:889-897.

17. Salvi S, Barnes PJ. Is exposure to biomass smoke the biggest risk factor for COPD globally? Chest. $2010 \mathrm{Jul} ; 138(1): 3-6$. 